\title{
Hot topic: Accuracy of refractometry as an indirect method to measure failed transfer of passive immunity in dairy calves fed colostrum replacer and maternal colostrum
}

\author{
A. J. Lopez, ${ }^{1}$ M. A. Steele, ${ }^{1}$ M. Nagorske, ${ }^{2}$ R. Sargent, ${ }^{2}$ and D. L. Renaud ${ }^{3 *}$ \\ ${ }^{1}$ Department of Animal Biosciences, Animal Science and Nutrition, University of Guelph, Guelph, Ontario, Canada N1G 1Y2 \\ ${ }^{2}$ The Saskatoon Colostrum Company Ltd., Saskatoon, SK, Canada S7K 6A2 \\ ${ }^{3}$ Department of Population Medicine, University of Guelph, Guelph, Ontario, Canada N1G 1Y2
}

\begin{abstract}
Serum total protein (STP) refractometry is a widely used indicator of failed transfer of passive immunity (FTPI), defined as serum IgG concentrations of $<10$ $\mathrm{mg} / \mathrm{mL}$ or STP levels $<5.2 \mathrm{~g} / \mathrm{dL}$ measured at $24 \mathrm{~h}$ of life. However, recent reports have demonstrated that refractometry could be inaccurate at estimating serum IgG concentrations and FTPI when calves are fed colostrum replacer (CR). The objective of this study was to evaluate the accuracy of STP measurements to estimate FTPI in calves fed CR compared with calves fed maternal colostrum. Blood was collected from dairy calves fed maternal colostrum $(\mathrm{n}=927)$ or colostrumderived CR $(\mathrm{n}=1,258)$ and analyzed for STP and serum IgG. Serum total protein was measured with a digital refractometer, whereas radial immunodiffusion was used to determine IgG concentrations. Calves fed maternal colostrum had a mean STP of $5.80 \pm 0.72$ (standard deviation) $\mathrm{g} / \mathrm{dL}$ and a mean IgG concentration of $22.81 \pm 10.14 \mathrm{mg} / \mathrm{mL}$, respectively, whereas calves fed CR had a mean STP and IgG concentration of $5.14 \pm 0.50 \mathrm{~g} / \mathrm{dL}$ and $12.78 \pm 4.60 \mathrm{mg} / \mathrm{mL}$, respectively. Rates of FTPI for calves fed maternal colostrum or CR were $4.2 \%$ and $27.26 \%$, respectively. Calves were considered to have FTPI if their IgG postcolostrum feeding was $<10 \mathrm{mg} / \mathrm{mL}$. Logistic and linear regression analyses were performed to determine cutoff points and existent relationships between STP and IgG. Serum total protein and $\operatorname{IgG}$ for calves fed maternal colostrum were highly correlated. In contrast, STP and IgG for calves fed CR were lowly correlated. A receiver operator characteristic curve analysis demonstrated that an STP cutoff point that could predict FTPI when calves are fed CR would be $4.9 \mathrm{~g} / \mathrm{dL}$ (sensitivity $=0.68$; specificity $=0.75$ ). This study suggests that current
\end{abstract}

Received May 23, 2020.

Accepted September 11, 2020.

*Corresponding author: renaudd@uoguelph.ca cutoff points used for STP inflates the number of calves estimated to have FTPI when they are fed CR.

Key words: calf, failed transfer of passive immunity, serum total protein, colostrum

\section{Hot Topic}

Calves are born with a naïve immune system and must acquire specific immune defense mechanism through colostrum feeding (Bush and Staley, 1980). Transfer of passive immunity is the process by which calves absorb immunoglobulins via colostrum feeding (Davis and Drackely, 1998). Calves are categorized as having a failed transfer of passive immunity (FTPI) when their serum IgG concentration is $<10 \mathrm{mg} / \mathrm{mL}$ or their serum total protein $(\mathbf{S T P})$ is $<5.2 \mathrm{~g} / \mathrm{dL}$ at $24 \mathrm{~h}$ of life (Calloway et al., 2002; Quigley, 2004; Godden, 2008). This categorization is based on trials that demonstrated that heifer calves with serum IgG concentrations $<10 \mathrm{mg} /$ $\mathrm{mL}$ had higher risks of mortality rates (Besser et al., 1991; Wells et al., 1996; Furman-Fratczak et al., 2011), and has not changed in several years (Gay, 1983). In addition, recent studies conducted by Gelsinger et al. (2015), Cummins et al. (2017), Lago et al. (2018), and Saldana et al. (2019) have used this threshold to classify FTPI in newborn calves.

A FTPI is not a disease, but a condition that makes calves susceptible to diseases during the first weeks of life (Stott et al., 1979; Weaver et al., 2000). A recent meta-analysis highlighted this increased susceptibility, identifying that calves with FTPI had an increased risk of mortality, bovine respiratory disease, and diarrhea as well as a decreased ADG (Raboisson et al., 2016). Moreover, Raboisson et al. (2016) identified increased on-farm costs associated with calves with FTPI; especially the increased use of antimicrobials to control the health disorders, namely diarrhea and bovine respiratory disease.

Failed transfer of passive immunity can be determined by measuring IgG concentrations either by direct or in- 
direct methods. The most commonly used method that directly measures IgG is radial immunodiffusion assay (RID); however, ELISA can also directly measure IgG (Gelsinger et al., 2015). The RID is considered to be the reference standard for serum IgG measurement (Tyler et al., 1996; Wilm et al., 2018). When using RID, FTPI is considered as serum IgG concentrations $<10 \mathrm{mg} / \mathrm{mL}$ at $24 \mathrm{~h}$ after birth (Shivley et al., 2018); it has been previously defined by Besser et al. (1991) and Furman-Fratczak et al. (2011). Despite been the reference standard test, this assay is time consuming, expensive, not applicable on-farm, requires laboratory procedures and gives results in approximately $24 \mathrm{~h}$ (Deelen et al., 2014; Renaud et al., 2018). Consequently, practical and simple indirect measures are often used to estimate levels of serum IgG or FTPI (Hernandez et al., 2016). The most common indirect method is STP using refractometry (Deelen et al., 2014). Refractometers use the degree of refraction to estimate total proteins in solutions (Chavatte et al., 1998), which is valuable because immunoglobulins constitute a major proportion of protein in newborn serum (Calloway et al., 2002). In addition, as the amount of nonimmunoglobulin proteins in serum is considered to be constant (Calloway et al., 2002), and thus the result of refractometry should directly relate to the levels of immunoglobulins transferred into circulation.

It has been reported that STP is highly correlated with serum IgG and, as such, is commonly used to classify FTPI (McBeath et al., 1971; Deelen et al., 2014; Renaud et al., 2018). A wide range of STP thresholds (4.0-8.0 g/dL; Buczinski et al., 2018) have been used to classify FTPI. Despite this variation, Buczinski et al. (2018) concluded that an STP threshold of $<5.2 \mathrm{~g} / \mathrm{dL}$ ( sensitivity $=76.1 \%$; specificity $=89 \%$ ) was the most accurate for classifying FTPI in calves fed maternal colostrum. However, the authors did not include studies within the meta-analysis where CR had been fed (Buczinski et al., 2018), and consequently their STP threshold of $<5.2 \mathrm{~g} / \mathrm{dL}$ may not accurately represent FTPI in calves fed CR. Similarly, an earlier study by Quigley et al. (2002) suggested that current STP thresholds were developed from calves fed maternal colostrum; therefore, the cutoff point to classify FTPI in calves fed $\mathrm{CR}$ is unclear.

Colostrum replacers (CR) have been developed as an alternative for farmers who lack high quality (IgG content), pathogen-free maternal colostrum or an adequate volume of maternal colostrum (Lopez et al., 2020). More producers are starting to use CR, with $19.1 \%$ of all operations in the United States using CR (NAHMS, 2014); however, low STP readings in newborn calves are reportedly becoming more frequent even when calves have serum $\operatorname{IgG}$ concentrations $\geq 10$ $\mathrm{mg} / \mathrm{mL}$. In addition, Quigley et al. (2002), Lago et al. (2018) and Lopez et al. (2020) highlighted that when calves are fed CR, the STP threshold of $\leq 5.2 \mathrm{~g} / \mathrm{dL}$ is inaccurate to predict FTPI. This threshold facilitates a misconception in which calves are falsely assumed to have FTPI (Donovan et al., 1998; Calloway et al., 2002; Priestley et al., 2013). This inaccuracy in STP readings could be due to different nonimmunoglobulin proteins in CR compared with maternal colostrum. Specifically, Priestley et al. (2013) and Leeflang (2014) found that CR have protein profiles that differ from maternal colostrum and would affect serum refractometry readings of CR-fed calves.

Thus, the objective of this cross-sectional diagnostic accuracy study was to evaluate the ability of STP refractometry measures to estimate serum IgG and FTPI in calves fed maternal colostrum and CR. We hypothesized that a low correlation would exist between STP and serum IgG for calves fed CR in contrast to a high correlation for calves fed maternal colostrum.

This study used pre- and postcolostrum STP and serum IgG data (Saskatoon Colostrum Company Ltd.; SCCL; Saskatoon, SK, Canada) from calves fed maternal colostrum $(\mathrm{n}=927)$ or SCCL colostrum-derived CR $(\mathrm{n}=1,258)$. Data included samples from male and female newborn Holstein calves; there was no selection based on sex. The sample size of this study was based on the number of samples available in an existing data set provided by SCCL. Data were collected from 85 dairy farms located in the United States (WI, MN, and $\mathrm{CA}$ ) and Canada (BC, AB, SK, MB, ON, and QC) from 2009 to 2017. The SCCL colostrum-derived CR fed to calves were as follows: Calf's Choice Total Gold (IgG: $\geq 26 \%$; CP: $58 \%$, crude fat: $18 \%$; DM: $94 \%$ ), Calf's Choice Total (IgG: $\geq 21 \%$; CP: $55 \%$, crude fat: $20 \%$; DM: $94 \%$ ), and Calf's Choice Total HiCal (IgG: $\geq 14$, CP: $48 \%$; crude fat: 23\%; DM: 94\%). Colostrum feeding protocols likely differed in the commercial farms, but STP and serum IgG samples were retrospectively collected for the purpose of validating FTPI thresholds in commercial dairy farms. The inclusion criteria did not change over the course of the trial, as all calves that were sampled at $0 \mathrm{~h}$ after birth and 24 to $48 \mathrm{~h}$ after colostrum feeding were included in the analyses.

Precolostrum blood samples were collected immediately before colostrum feeding, and postcolostrum blood samples were collected between 24 and $48 \mathrm{~h}$ after birth. Blood samples were taken via jugular venipuncture using serum vacutainer tubes without anticoagulant, left at room temperature for $3 \mathrm{~h}$ to coagulate, then centrifuged at $3,000 \times g$ for $15 \mathrm{~min}$ at room temperature $\left(\sim 20^{\circ} \mathrm{C}\right)$ to separate serum. Thereafter, serum was transferred to $2-\mathrm{mL}$ microtubes and frozen at $-20^{\circ} \mathrm{C}$. Serum samples were then sent to SCCL for further 
laboratory analysis for STP and serum IgG. Serum total protein was measured using a digital refractometer (PA2020X Misco Palm Abbe Dual Scale, Solon, OH), and serum IgG was analyzed by an RID performed by SCCL, as described by Chelack et al. (1993), and more recently by Shivley et al. (2018). In brief, RID is an assay that quantifies IgG by the reaction between antibodies in a plate and antigens present in serum samples. After $24 \mathrm{~h}$, a precipitin ring is formed in a well at room temperature. The ring's diameter is then measured using a scale loupe, and the measurement is used in a logarithmic formula to determine the $\operatorname{IgG}$ concentration of the sample.

Statistical analysis was conducted using SAS (University Edition; SAS Institute Inc., Cary, NC). Data were imported from Microsoft Excel (version 16.16.21; Microsoft Corporation., Redmond, WA) into SAS. Calves with precolostrum serum IgG $\geq 2 \mathrm{mg} / \mathrm{mL}$ were presumed to have nursed before colostrum feeding and were removed from the analysis, according to SCCL guidelines. Moreover, other researchers have also removed calves with serum IgG above $0 \mathrm{mg} / \mathrm{mL}$ before colostrum feeding, with the assumption that they might have suckled colostrum from their dam, which could affect serum IgG analyses at $24 \mathrm{~h}$ (Gelsinger et al., 2015; Saldana et al., 2019). This exclusion criterion has been used because serum IgG values at birth are almost nonexistent $(0.1-0.3 \mathrm{mg} / \mathrm{mL}$; Gelsinger et al., 2015). The complete data set provided by SCCL had a total of 950 and 1,339 blood samples from calves fed maternal colostrum and CR, respectively. However, 23 $(2.42 \%)$ calves fed maternal colostrum and 81 (6.04\%) calves fed CR were removed based on serum IgG $\geq 2.0$ $\mathrm{mg} / \mathrm{mL}$ before colostrum feeding. As a result, only 927 and 1,258 blood samples from calves fed maternal colostrum and CR, respectively, were used in the final analysis. No additional calves were removed from the study, as calves with severe dehydration or sickness at the postcolostrum feeding sampling time point did not have samples taken. Calves were diagnosed for dehydration whenever they had severe diarrhea (i.e., eye recession, prolonged skin tent, difficult in rising) and were considered sick if they presented diarrhea or septicemia in the first hours of life.

Data were analyzed for normality and descriptive statistics using the UNIVARIATE procedure of SAS. Normality was declared using Shapiro-Wilk as criterion. The final model only included blood samples collected after maternal colostrum or CR feeding. The STP and serum IgG values postcolostrum feeding were analyzed using PROC MEANS. Significance was declared at $P<$ 0.05 . Additionally, STP and serum IgG postfeeding data were analyzed using the PROC CORR. The regression procedure from SAS was used to determine whether a linear relationship existed between serum IgG concentration and STP concentration, with STP as the predictor variable and serum IgG as the outcome variable. Serum total protein and serum IgG were also analyzed using receiver operator characteristic (ROC) curves to determine the STP cutoff point necessary to predict FTPI, defined as a serum IgG $<10 \mathrm{mg} / \mathrm{mL}$. Youden's index was used to determine the cutoff point that maximized both sensitivity and specificity (Youden, 1950). A subset of data including calves with a serum IgG concentration $\geq 10 \mathrm{mg} / \mathrm{mL}$ was created. This subset was analyzed using the frequency procedure to visualize the distribution of STP values when calves achieved a successful passive transfer of immunity, defined as a serum $\mathrm{IgG}$ concentration $\geq 10 \mathrm{mg} / \mathrm{mL}$. All values are reported as mean \pm standard deviation. Additionally, an interval likelihood ratio analysis was done using the PROC GLIMMIX and PROC FREQ in SAS.

A total of $39(4.20 \%)$ calves fed maternal colostrum had FTPI after colostrum feeding, defined as serum $\operatorname{IgG}<10 \mathrm{mg} / \mathrm{mL}$ via RID. Serum total protein for calves fed maternal colostrum was $5.80 \pm 0.72 \mathrm{~g} / \mathrm{dL}$, whereas their mean serum IgG was $22.81 \pm 10.14 \mathrm{mg} /$ $\mathrm{mL}$. Postcolostrum STP and serum IgG showed a high, positive correlation, with STP explaining $81 \%$ of the variation in the serum IgG concentrations $\left(\mathrm{R}^{2}=0.81 ; P\right.$ $<0.0001)$ (Figure 1a). These results demonstrated that STP explained a substantial portion of the variation of $\mathrm{IgG}$, and that it was an adequate predictor of serum IgG in calves fed maternal colostrum. When evaluating calves fed maternal colostrum, a ROC analysis reported that these data had an area under the curve of 0.96 (95\% confidence interval: 0.94-0.98). According to the ROC analysis and using the Youden Index, the STP cutoff point for FTPI was determined to be 5.0 $\mathrm{g} / \mathrm{dL}$, with a sensitivity of 0.92 (95\% confidence interval: $0.74-0.95)$ and specificity of 0.90 (95\% confidence interval: $0.35-0.61$ ), for calves fed maternal colostrum. These results demonstrated that a high correlation exists between STP and serum IgG when evaluating calves fed maternal colostrum. This high correlation was corroborated by the meta-analysis performed by Buczinski et al. (2018), where the STP cutoff points of $5.2 \mathrm{~g} / \mathrm{dL}$ and $5.5 \mathrm{~g} / \mathrm{dL}$ were defined as the most accurate to predict FTPI, with sensitivities and specificities of 76.1 and $86.3 \%$ for $5.2 \mathrm{~g} / \mathrm{dL}$, and 88.2 and $77.9 \%$ for $5.5 \mathrm{~g} / \mathrm{dL}$.

A total of $343(27.26 \%)$ calves fed CR had FTPI after colostrum feeding, defined as serum IgG $<10 \mathrm{mg} /$ $\mathrm{mL}$ via RID. Serum total protein for calves fed CR was $5.14 \pm 0.50 \mathrm{~g} / \mathrm{dL}$, whereas their mean serum $\mathrm{IgG}$ was $12.78 \mathrm{mg} / \mathrm{mL} \pm 4.60 \mathrm{mg} / \mathrm{mL}$. A low correlation was found between STP and serum IgG, with STP only explaining $40 \%$ of the variation in the level of serum 

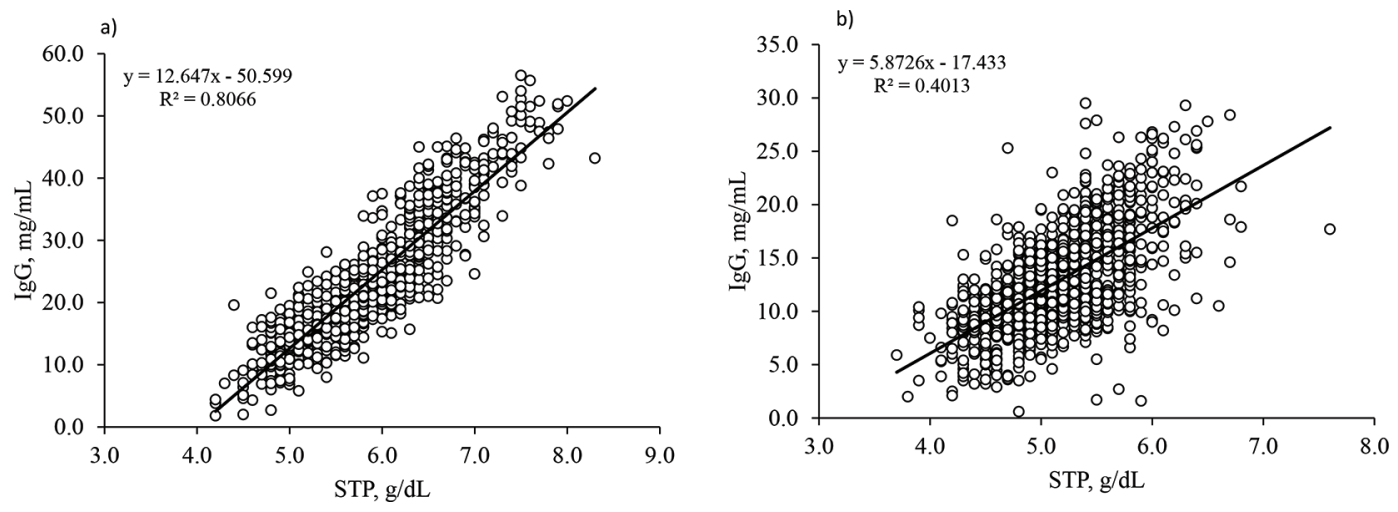

Figure 1. Linear regression relationship between serum total protein (STP) and serum IgG for 927 calves fed maternal colostrum (panel a) or 1,258 calves fed colostrum replacer (panel b). Slope for calves fed colostrum replacer was 5.87 , which is less than the slope for calves fed maternal colostrum (12.65).

$\operatorname{IgG}\left(\mathrm{R}^{2}=0.40 ; P<0.0001 ;\right.$ Figure 1b). The coefficient of determination between STP and serum IgG found in this study was lower than previously reported $\left(\mathrm{R}^{2}=\right.$ 0.59-0.62; Mowrey, 2001; Quigley et al., 2002) for calves fed CR. However, these results collectively demonstrate that STP does not explain the majority of the variation in serum IgG, and consequently does not accurately predict serum IgG concentrations in calves fed CR. The ROC analysis in this study reported that these data had an area under the curve of 0.78 (95\% confidence interval: $0.75-0.80$ ), which is lower than the area under the curve reported for calves fed maternal colostrum. According to the ROC analysis and using the Youden Index, the STP threshold was determined to be $4.9 \mathrm{~g} /$ $\mathrm{dL}$, with a sensitivity of 0.68 (95\% confidence interval: $0.54-0.81)$ and specificity of 0.75 (95\% confidence interval: 0.32 to 0.61 ). These results suggested that a lower STP cutoff point should be used to predict FTPI in calves fed SCCL colostrum-derived CR compared with calves fed maternal colostrum. However, even with a lower threshold, the low sensitivity and specificity of this threshold further compromises the use of STP use as an indicator of FTPI for CR-fed calves. The low sensitivity will result in a greater proportion of false negatives, with those classified as FTPI actually having successful passive transfer of immunity. The cutoff point of $4.9 \mathrm{~g} / \mathrm{dL}$ found in this study will not greatly improve the correct identification of true positives and true negatives, but does underline that an alternate STP cutoff point should be developed to ensure a high sensitivity and specificity when classifying FTPI in calves fed CR. Due to the inadequate sensitivities and specificities from the ROC analysis performed in this study, an additional analysis of interval likelihood ratios was performed (Table 1). Interval likelihood ratio is defined as the probability of the test result when the condition is present divided by the probability of the test result when the condition is absent. The interval likelihood ratio calculation for 1 specific range (i.e., $4.0-4.5)$ was done by dividing the percentage (\%) of calves with FTPI by the percentage of calves with a success of passive transfer that fell in that same range. From the interval likelihood ratio calculation in Table 1 , we concluded that the likelihood that STP will identify FTPI in calves fed maternal colostrum is high in the ranges from 4.0 to 5.0. In contrast, the likelihood ratios from calved fed $\mathrm{CR}$ are considerably low from the ranges of 4.0 to 6.5 . This led to the assumption that the probability of identifying FTPI condition in calves fed $\mathrm{CR}$ is low; which is in concordance with the correlation between STP and IgG. Overall results suggested that STP refractometry is not suitable for correcting identifying FTPI in calves fed CR. As a result, refractometry should only be used to identify trends and should not be the only assessment tool in a calf-rearing program.

Although the majority of CR-fed calves $(72.74 \%)$ had serum IgG values $\geq 10 \mathrm{mg} / \mathrm{mL}$, some had an STP below the FTPI threshold of $5.2 \mathrm{~g} / \mathrm{dL}$ (Calloway et al., 2002). The low STP concentrations could lead to FTPI misinterpretation if producers rely solely on the use of refractometry to determine FTPI. The results indicated that CR-fed calves can achieve successful immunity and serum IgG values above $10 \mathrm{mg} / \mathrm{mL}$, despite having low STP concentrations. The frequency distributions of STP values for calves with serum IgG concentrations $\geq 10 \mathrm{mg} / \mathrm{mL}$, either fed maternal colostrum (n $=888)$ or CR $(\mathrm{n}=915)$, are presented in Figure 2a and b, respectively. Only $14.9 \%$ of calves fed maternal colostrum with successful transfer of passive immunity had STP values below $5.2 \mathrm{~g} / \mathrm{dL}$ (Figure 2a), supporting that STP is a good predictor of successful immunity when calves are fed maternal colostrum. In contrast, $41.2 \%$ of CR-fed calves had STP protein values $<5.2$ $\mathrm{g} / \mathrm{dL}$ (Figure 2b), even with successful transfer of 
a)

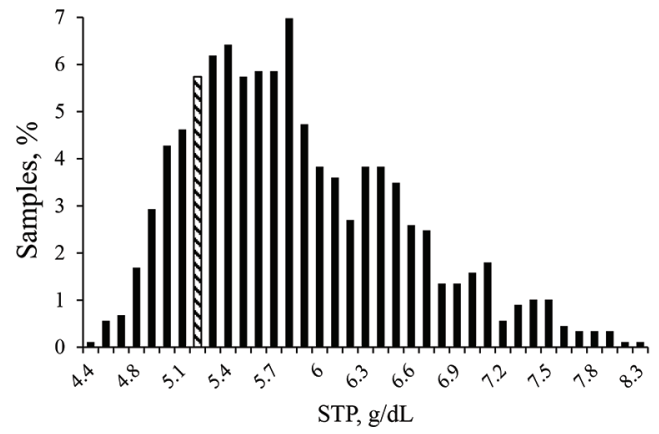

b)

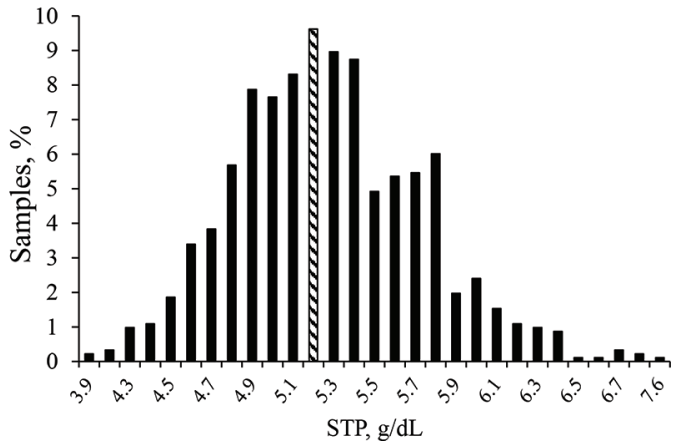

Figure 2. Frequency distributions of serum total protein (STP) for maternal colostrum-fed calves (n $=888$, panel a) or colostrum replacerfed calves ( $\mathrm{n}=915$, panel b) with serum IgG concentrations $>10 \mathrm{mg} / \mathrm{mL}$ (success of passive transfer). The dashed column represents a STP value of $5.2 \mathrm{~g} / \mathrm{dL}$.

passive immunity, further highlighting that currently established thresholds are inaccurate to predict FTPI in calves that have consumed CR.

The incongruency of STP as an adequate predictor of serum IgG concentration and FTPI has also been discussed by Quigley et al. (2002), Lago et al. (2018), and Lopez et al. (2020). Similar to our study, others have reported that although CR-fed calves had serum IgG concentrations $\geq 10 \mathrm{mg} / \mathrm{mL}$, STP was less than 5.0 or $5.2 \mathrm{~g} / \mathrm{dL}$ (Quigley et al., 2002; Lago et al., 2018; Lopez et al., 2020). Quigley et al. (2002) reported that calves fed CR had a mean STP of $5.0 \mathrm{~g} / \mathrm{L}$ and serum IgG of $13.6 \mathrm{mg} / \mathrm{mL}$. Lago et al. (2018) reported that calves fed CR had a mean STP of $5.2 \mathrm{~g} / \mathrm{dL}$, despite serum IgG being $19.6 \mathrm{mg} / \mathrm{mL}$. Similarly, Lopez et al. (2020) reported an STP of $4.5 \mathrm{~g} / \mathrm{dL}$, lower than the mean reported in the current study, and serum IgG was 16.9 $\mathrm{mg} / \mathrm{mL}$. The low STP values found in CR-fed calves led Quigley et al. (2002), Lago et al. (2018), and Lopez et al. (2020) to conclude that the STP cutoff point of 5.2 $\mathrm{g} / \mathrm{dL}$ was inaccurate at predicting FTPI. As a result, Quigley et al. (2002) and Lopez et al. (2020) suggested new STP cutoff points. In concordance with our study, these authors also mentioned that lower cutoff points should be used when calves are fed CR. Quigley et al. (2002) suggested that a STP $<4.9 \mathrm{~g} / \mathrm{dL}$ would be a better predictor of serum IgG concentrations $<10 \mathrm{mg} /$ $\mathrm{mL}$, which is similar to the $4.9 \mathrm{~g} / \mathrm{dL}$ STP cutoff value determined in our study. Using a ROC analysis between STP and serum IgG, Lopez et al. (2020) found that a STP threshold of $4.2 \mathrm{~g} / \mathrm{dL}$ (sensitivity $=1.0$; specificity $=0.58$ ) at $24 \mathrm{~h}$ of life would be a better predictor of FTPI when calves are fed CR products. However, it is important to note that STP cutoff points developed us-

Table 1. Serum total protein $(\mathrm{STP})$ threshold ranges in newborn calves fed maternal colostrum $(\mathrm{n}=927)$ or colostrum replacer $(\mathrm{n}=1,258)$

\begin{tabular}{|c|c|c|c|c|c|c|c|c|c|}
\hline \multirow[b]{2}{*}{ Source } & \multirow[b]{2}{*}{ STP } & \multirow[b]{2}{*}{ Count } & \multicolumn{2}{|c|}{ FTPI $^{1}$} & \multicolumn{2}{|c|}{ Success $^{2}$} & \multirow{2}{*}{$\begin{array}{l}\text { Likelihood } \\
\text { ratio }\end{array}$} & \multicolumn{2}{|c|}{$95 \% \mathrm{CI}$} \\
\hline & & & No. & $\%$ & No. & $\%$ & & Lower & Upper \\
\hline \multirow[t]{8}{*}{ Maternal colostrum } & $<4.0$ & 0 & - & - & - & - & - & - & - \\
\hline & $4.0-<4.6$ & 6 & 5 & 12.82 & 1 & 0.11 & 113.85 & 0.04 & 0.08 \\
\hline & $4.5-<5.0$ & 78 & 26 & 66.67 & 52 & 5.86 & 11.38 & 0.30 & 0.36 \\
\hline & $5.0-<5.6$ & 250 & 8 & 20.51 & 242 & 27.25 & 0.75 & 0.59 & 0.66 \\
\hline & $5.5-<6.0$ & 259 & 0 & 0.00 & 259 & 29.17 & 0.00 & 0.77 & 0.83 \\
\hline & $6.0-<6.6$ & 158 & 0 & 0.00 & 158 & 17.79 & 0.00 & 0.89 & 0.93 \\
\hline & $6.5-<7.0$ & 100 & 0 & 0.00 & 100 & 11.26 & 0.00 & - & - \\
\hline & $7.0-8.0$ & 76 & 0 & 0.00 & 76 & 8.56 & 0.00 & - & - \\
\hline \multirow[t]{8}{*}{ Colostrum replacer } & $<4.0$ & 7 & 5 & 0.55 & 2 & 0.58 & 0.94 & 0.00 & 0.00 \\
\hline & $4.0-<4.6$ & 82 & 60 & 6.56 & 22 & 6.41 & 1.02 & 0.02 & 0.04 \\
\hline & $4.5-<5.0$ & 375 & 168 & 18.36 & 207 & 60.35 & 0.30 & 0.22 & 0.28 \\
\hline & $5.0-<5.6$ & 483 & 87 & 9.51 & 396 & 115.45 & 0.08 & 0.65 & 0.71 \\
\hline & $5.5-<6.0$ & 237 & 20 & 2.19 & 217 & 63.27 & 0.03 & 0.91 & 0.94 \\
\hline & $6.0-<6.6$ & 66 & 3 & 0.33 & 63 & 18.37 & 0.02 & 0.98 & 1.00 \\
\hline & $6.5-<7.0$ & 7 & 0 & 0.00 & 7 & 2.04 & - & - & - \\
\hline & $7.0-8.0$ & 1 & 0 & 0.00 & 1 & 0.29 & - & - & - \\
\hline
\end{tabular}

${ }^{1} \mathrm{FTPI}=$ defined as a serum IgG concentration $<10 \mathrm{mg} / \mathrm{mL}$.

${ }^{2}$ Success $=$ defined as a serum IgG concentration $>10 \mathrm{mg} / \mathrm{mL}$. 
ing a specific $\mathrm{CR}$ or performance of one $\mathrm{CR}$ should not be extrapolated to other CR products (Godden et al., 2009), due to their different manufacturing techniques and nutritional compositions.

The inconsistency of STP by refractometry as a method to adequately identify FTPI in newborn calves is complex (Buczinski et al., 2018) and not completely understood. Research has shown that different CR products have different protein profiles (Priestley et al., 2013; Leeflang, 2014) and fat contents (Lopez et al., 2020) compared with maternal colostrum, which may contribute to the observed inconsistencies. For example, Lago et al. (2018) fed calves whey-derived CR and stated that the low STP values found in blood of CR-fed calves could be attributed to the lesser quantities of protein present in the CR. As a result, they hypothesized that successful passive transfer could be achieved at lower refractometry readings when calves were fed CR (Lago et al., 2018).

Colostrum replacers differ widely in composition. They can be derived from blood or serum, egg, and lacteal sources (colostrum, whey, or milk; Quigley, 2004) and their manufacturing varies depending on the fractioning techniques implemented, ratio and type of non-IgG proteins, and amount of lactose (Mee et al., 1996; Arthington et al., 2000; Quigley et al., 2001). For example, Quigley et al. (2002) used a plasma-derived CR with a composition of IgG concentrate (21.2\%), lactose, high fructose corn syrup, and dry fat blend $(7 \%$ CP, $60 \%$ fat), whereas Lopez et al. (2020) used a wheybased CR with a higher IgG concentration of $40.64 \%$ that was devoid of fat and casein content. However, for the present study, the CR were all derived from natural bovine colostrum with IgG concentrations of 26, 21, and $14 \%$ with protein (48-58\%) and fat contents (18, 20 , and $23 \%$ ) not having major variation. These differing compositions could provide some rationale for the low performance of STP as a measure of serum IgG and FTPI when CR is fed.

In addition to $\mathrm{CR}$ composition and manufacturing processes, refractometry readings can be affected by additional factors, such as dehydration (Buczinski et al., 2018). In dehydrated calves, blood components and protein contents become more concentrated and, as a result, their total STP is increased and might appear satisfactory (Buczinski et al., 2018). As a consequence, calves could be mistakenly classified as having a successful transfer of passive immunity based on their elevated STP due to dehydration. Also, sick calves (i.e., septicemia or diarrhea) experience systemic inflammatory processes that could elevate their IgG levels, causing elevated serum IgG concentrations (Fecteau et al., 2013). Sick calves could also be wrongly classified as having a successful transfer of passive immunity because the serum refractance will be increased due to the higher presence of inflammatory markers (Fecteau et al., 2013).

Assays to determine IgG that require laboratory work, such as the zinc sulfite turbidity test, $\gamma$-glutamyl transferase, whole-blood glutaralehyde coagulation test, sodium sulfate turbidity test, and ELISA, have been widely used to predict serum IgG concentrations (Tyler et al., 1996; Parish et al., 1997; Weaver et al., 2000). However, these tests are not available to most producers that need rapid results (Tyler et al., 1996; Parish et al., 1997; Weaver et al., 2000). Currently, simple on-farm IgG tests that accurately predict FTPI are scarce, inaccurate, or have not been tested thoroughly. Some of the on-farm IgG tests available include semiquantitative antibody test (ZAPvet Bovine IgG test, NOW Diagnostics Toronto, Ontario, Canada), quick IgG test (Plasma Calf IgG Midland Quick Test Kit, Midland Bioproducts Corporation, Boone, IA), and IgGCheck Calf IgG Test Kit (PortaCheck, Moorestown, NJ). Elsohaby and Keefe (2015) evaluated the effectiveness of semiquantitative antibody test to detect FTPI, where 202 blood samples were analyzed and compared the FTPI rates obtained with the semiquantitative antibody test versus RID assay. They reported that it has the potential to be a rapid on-farm test to detect FTPI (sensitivity $=0.82$ and specificity $=0.65$ ). However, Renaud et al. (2018) evaluated the same test in calves arriving at a milk-fed veal facility and stated that this test poorly detected FTPI (sensitivity $=0.77$; specificity $=0.44)$. Another on-farm test that has been evaluated is a commercial quick IgG test. Stilwell and Carvalho (2011) found the Quick Test Kit blood IgG immunoassay accurately detects serum IgG concentrations $\geq 10 \mathrm{mg} / \mathrm{mL}$ (sensitivity $=0.93$; specificity $=$ 0.88 ); however, to the author's knowledge, this test has not been widely evaluated. Moreover, another alternative that could be used to estimate serum IgG is Brix refractometry (Deelen et al., 2014), as Brix values are highly correlated with IgG $(\mathrm{r}=0.93$; Deelen et al., 2014). Future studies should evaluate whether a similar low correlation is found between Brix values and IgG when a $\mathrm{CR}$ is fed. As producers require simple, quick, and affordable on-farm tools to assess FTPI in calves, it is necessary to develop or validate an accurate on-farm test that directly measures serum IgG, especially when calves are fed CR, as STP is an inadequate predictor of FTPI.

In conclusion, the results of this study demonstrated that even low STP concentrations in CR-fed calves do not correlate well with FTPI, as defined by serum IgG $\geq 10 \mathrm{mg} / \mathrm{mL}$. Further investigation is needed to clearly develop an alternate STP threshold to define FTPI for CR-fed calves. The discrepancy between STP and se- 
rum IgG for FTPI thresholds in CR-fed calves needs to be clarified to correctly assess calf health on-farm and effectively manage calf rearing programs.

\section{ACKNOWLEDGMENTS}

The authors thank Michael Chubb (Saskatoon Colostrum Company, Saskatoon, SK, Canada) for his support and assessment. Also, the authors thank Alberta Agriculture (Edmonton, AB, Canada), Alberta Milk (Edmonton, AB, Canada), the BC Dairy Association (Burnaby, BC, Canada), SaskMilk (Regina, SK, Canada), the Dairy Farmers of Manitoba (Winnipeg, MB, Canada), the Saskatoon Colostrum Company Ltd. (Saskatoon, SK, Canada), Westgen (Abbottsford, BC, Canada), Lallemand (Montreal, QC, Canada), and the Natural Sciences and Engineering Research Council of Canada (NSERC; Ottawa, ON, Canada) for the funding for A. J. Lopez in his graduate studies at the University of Guelph. The authors have not stated any conflicts of interest.

\section{REFERENCES}

Arthington, J. D., M. B. Cattell, J. D. Quigley III, G. C. McCoy, and W. L. Hurley. 2000. Passive immunoglobin transfer in newborn calves fed colostrum or spray-dried serum protein alone or as a supplement to colostrum of varying quality. J. Dairy Sci. 83:28342838. https://doi.org/10.3168/jds.S0022-0302(00)75183-6.

Besser, T. E., C. C. Gay, and L. Pritchett. 1991. Comparison of 3 methods of feeding colostrum to dairy calves. J. Am. Vet. Med. Assoc. 198:419-422.

Buczinski, S., E. Gicquel, G. Fecteau, Y. Takwoingi, M. Chigerwe, and J. Vandeweerd. 2018. Systematic review and meta-analysis of diagnostic accuracy of serum refractometry and Brix refractometry for the diagnosis of inadequate transfer of passive immunity in calves. J. Vet. Intern. Med. 32:474-483. https://doi.org/10.1111/ jvim.14893.

Bush, L. J., and T. E. Staley. 1980. Absorption of colostral immunoglobulins in newborn calves. J. Dairy Sci. 63:672-680. https://doi .org/10.3168/jds.S0022-0302(80)82989-4.

Calloway, C. D., J. W. Tyler, R. K. Tessman, D. Hostetler, and J. Holle. 2002. Comparison of refractometers and test endpoints in the measurement of serum protein concentration to assess passive transfer status in calves. J. Am. Vet. Med. Assoc. 221:1605-1608. https://doi.org/10.2460/javma.2002.221.1605.

Chavatte, P., F. Clement, R. Cash, and J. F. Grognet. 1998. Field determination of colostrum quality by using a novel, practical method. Pages 206-209 in AAEP Proc. 44, Lexington, KY. American Association of Equine Practitioners (AAEP), Baltimore, MD.

Chelack, B. J., P. S. Morley, and D. M. Haines. 1993. Evaluation of methods for dehydration of bovine colostrum for total replacement of normal colostrum in calves. Can. Vet. J. 34:407-412.

Cummins, C., D. Berry, J. Murphy, I. Lorenz, and E. Kennedy. 2017. The effect of colostrum storage conditions on dairy heifer calf serum immunoglobulin $\mathrm{G}$ concentration and preweaning health and growth rate. J. Dairy Sci. 100:525-535. https://doi.org/10.3168/ jds.2016-10892.

Davis, C. L., and J. K. Drackely. 1998. The Development, Nutrition, and Management of the Young Calf. Iowa State University Press, Ames, IA.

Deelen, S. M., T. L. Ollivett, D. M. Haines, and K. E. Leslie. 2014. Evaluation of a Brix refractometer to estimate serum immuno- globulin G concentration in neonatal dairy calves. J. Dairy Sci 97:3838-3844. https://doi.org/10.3168/jds.2014-7939.

Donovan, G. A., I. R. Dohoo, D. M. Montgomery, and F. L. Bennett. 1998. Associations between passive immunity and morbidity and mortality in dairy heifers in Florida, USA. Prev. Vet. Med. 34:3146. https://doi.org/10.1016/S0167-5877(97)00060-3.

Elsohaby, I., and G. P. Keefe. 2015. Preliminary validation of a calfside test for diagnosis of failure of transfer of passive immunity in dairy calves. J. Dairy Sci. 98:4754-4761. https://doi.org/10.3168/ jds.2014-9027.

Fecteau, G., J. Arsenault, J. Paré, D. C. Van Metre, C. A. Holmberg, and B. P. Smith. 2013. Prediction of serum IgG concentration by indirect techniques with adjustment for age and clinical and laboratory covariates in critically ill newborn calves. Can. J. Vet. Res. 77:89-94.

Furman-Fratczak, K., A. Rzasa, and T. Stefaniak. 2011. The influence of colostral immunoglobulin concentration in heifer calves' serum on their health and growth. J. Dairy Sci. 94:5536-5543. https:// doi.org/10.3168/jds.2010-3253.

Gay, C. C. 1983. Failure of passive transfer of colostral immunoglobulins and neonatal disease in calves: A review. Pages 346-364 in Proc. 4th Int. Symp. Neonatal Dis. Vet. Infect. Dis. Org., Saskatoon, SK, Canada. Veterinary Infectious Disease Organization, Saskatoon, SK, Canada.

Gelsinger, S. L., A. M. Smith, C. M. Jones, and A. J. Heinrichs. 2015. Technical note: Comparison of radial immunodiffusion and ELISA for quantification of bovine immunoglobulin $\mathrm{G}$ in colostrum and plasma. J. Dairy Sci. 98:4084-4089. https://doi.org/10.3168/jds 2014-8491.

Godden, S. 2008. Colostrum management for dairy calves. Vet. Clin. North Am. Food Anim. Pract. 24:19-39. https://doi.org/10.1016/ j.cvfa.2007.10.005.

Godden, S. M., D. M. Haines, and D. Hagman. 2009. Improving passive transfer of immunoglobulins in calves. I: Dose effect of feeding a commercial colostrum replacer. J. Dairy Sci. 92:1750-1757. https://doi.org/10.3168/jds.2008-1846.

Hernandez, D., D. V. Nydam, S. M. Godden, L. S. Bristol, A. Kryzer, J. Ranum, and D. Schaefer. 2016. Brix refractometry in serum as a measure of failure of passive transfer compared to measured immunoglobulin $\mathrm{G}$ and total protein by refractometry in serum from dairy calves. Vet. J. 211:82-87. https://doi.org/10.1016/j.tvjl.2015 .11 .004 .

Lago, A., M. Socha, A. Geiger, D. Cook, N. Silva-del-Río, C. Blanc, R. Quesnell, and C. Leonardi. 2018. Efficacy of colostrum replacer versus maternal colostrum on immunological status, health, and growth of preweaned dairy calves. J. Dairy Sci. 101:1344-1354. https://doi.org/10.3168/jds.2017-13032.

Leeflang, M. M. G. 2014. Systematic reviews and meta-analyses of diagnostic test accuracy. Clin. Microbiol. Infect. 20:105-113. https: //doi.org/10.1111/1469-0691.12474.

Lopez, A. J., C. M. Jones, A. J. Geiger, and A. J. Heinrichs. 2020. Comparison of immunoglobulin $\mathrm{G}$ absorption in calves fed maternal colostrum, a commercial whey-based colostrum replacer, or supplemented maternal colostrum. J. Dairy Sci. 103:4838-4845. https://doi.org/10.3168/jds.2019-17949.

McBeath, D. G., W. Penhale, and E. Logan. 1971. An examination of the influence of husbandry on the plasma immunoglobulin level of the newborn calf, using a rapid refractometer test for assessing immunoglobulin content. Vet. Rec. 88:266-270. https://doi.org/10 $.1136 /$ vr.88.11.266 http://dx.doi.

Mee, J. F., K. J. O'farrell, P. Reitsma, and R. Mehra. 1996. Effect of a whey protein concentrate used as a colostrum substitute or supplement on calf immunity, weight gain, and health. J. Dairy Sci. 79:886-894. https://doi.org/10.3168/jds.S0022-0302(96)76437-8.

Mowrey, C. M. 2001. Influence of feeding pooled colostrum or colostrum replacement on IgG levels and evaluation of animal plasma as a milk replacer protein source. M.S. thesis, Department of Dairy Science, Virginia Tech, Blacksburg, VA.

NAHMS. 2014. Dairy Cattle Management Practices in the United States. USDA:APHIS, Fort Collins, CO. 
Parish, S. M., J. W. Tyler, T. E. Besser, C. C. Gay, and D. Krytenberg. 1997. Prediction of serum IgG1 concentration in Holstein calves using serum gamma glutamyltransferase activity. J. Vet. Intern. Med. 11:344-347. https://doi.org/10.1111/j.1939-1676.1997 .tb00478.x.

Priestley, D., J. H. Bittar, L. Ibarbia, C. A. Risco, and K. N. Galvão. 2013. Effect of feeding maternal colostrum or plasma-derived or colostrum-derived colostrum replacer on passive transfer of immunity, health, and performance of preweaning heifer calves. J. Dairy Sci. 96:3247-3256. https://doi.org/10.3168/jds.2012-6339.

Quigley, J. 2004. The role of oral immunoglobulins in systemic and intestinal immunity of neonatal calves. Diamond V Mills, Cedar Rapids, IA.

Quigley, J. D. III, C. J. Kost, and T. M. Wolfe. 2002. Absorption of protein and IgG in calves fed a colostrum supplement or replacer. J. Dairy Sci. 85:1243-1248. https://doi.org/10.3168/jds.S0022 -0302(02)74188-X.

Quigley, J. D., R. E. Strohbehn, C. J. Kost, and M. M. O’Brien. 2001. Formulation of colostrum supplements, colostrum replacers and acquisition of passive immunity in neonatal calves. J. Dairy Sci. 84:2059-2065. https://doi.org/10.3168/jds.S0022-0302(01)74650 -4 .

Raboisson, D., P. Trillat, and C. Cahuzac. 2016. Failure of passive immune transfer in calves: A meta-analysis on the consequences and assessment of the economic impact. PLoS One 11:e0150452. https: //doi.org/10.1371/journal.pone.0150452.

Renaud, D. L., T. F. Duffield, S. J. LeBlanc, and D. F. Kelton. 2018. Validation of methods for practically evaluating failed passive transfer of immunity in calves arriving at a veal facility. J. Dairy Sci. 101:9516-9520. https://doi.org/10.3168/jds.2018-14723.

Saldana, D. J., S. L. Gelsinger, C. M. Jones, and A. J. Heinrichs. 2019 Effect of different heating times of high-, medium-, and low-quality colostrum on immunoglobulin $\mathrm{G}$ absorption in dairy calves. J. Dairy Sci. 102:2068-2074. https://doi.org/10.3168/jds.2018-15542.
Shivley, C. B., J. E. Lombard, N. J. Urie, D. M. Haines, R. Sargent, C. A. Kopral, T. J. Earleywine, J. D. Olson, and F. B. Garry. 2018. Preweaned heifer management on US dairy operations: Part II. Factors associated with colostrum quality and passive transfer status of dairy heifer calves. J. Dairy Sci. 101:9185-9198. https:// doi.org/10.3168/jds.2017-14008.

Stilwell, G., and R. C. Carvalho. 2011. Clinical outcome of calves with failure of passive transfer as diagnosed by a commercially available IgG quick test kit. Can. Vet. J. 52:524-526.

Stott, G. H., D. B. Marx, B. E. Menefee, and G. T. Nightengale. 1979. Colostral immunoglobulin transfer in calves. IV. Effect of suckling. J. Dairy Sci. 62:1908-1913. https://doi.org/10.3168/jds .S0022-0302(79)83522-5.

Tyler, J. W., D. D. Hancock, S. M. Parish, D. E. Rea, T. E. Besser, S. G. Sanders, and L. K. Wilson. 1996. Evaluation of 3 assays for failure of passive transfer in calves. J. Vet. Intern. Med. 10:304-307. https://doi.org/10.1111/j.1939-1676.1996.tb02067.x.

Weaver, D. M., J. W. Tyler, D. C. VanMetre, D. E. Hostetler, and G. M. Barrington. 2000. Passive transfer of colostral immunoglobulins in calves. J. Vet. Intern. Med. 14:569-577. https://doi.org/10 $.1111 /$ j.1939-1676.2000.tb02278.x.

Wells, S. J., D. A. Dargatz, and S. L. Ott. 1996. Factors associated with mortality to 21 days of life in dairy heifers in the United States. Prev. Vet. Med. 29:9-19. https://doi.org/10.1016/S0167 -5877(96)01061-6.

Wilm, J., J. H. Costa, H. W. Neave, D. M. Weary, and M. A. von Keyserlingk. 2018. Serum total protein and immunoglobulin G concentrations in neonatal dairy calves over the first 10 days of age. J. Dairy Sci. 101:6430-6436. https://doi.org/10.3168/jds.2017-13553.

Youden, W. J. 1950. Index for rating diagnostic tests. Cancer 3:32-35. https://doi.org/10.1002/1097-0142(1950)3:1<32::AIDCNCR2820030106>3.0.CO;2-3. 